\title{
THE ROLE OF THE KIDNEY IN THE ETIOLOGY OF RENAL HYPERLIPEMIA ${ }^{1}$
}

\author{
By N. R. Di LUZIO AND C. RILEY HOUCK $\dagger$ \\ (From The Division of Physiology, University of Tennessee, Memphis, Tenn.)
}

(Submitted for publication June 14, 1956; accepted August 14, 1956)

Progressive and continuous increases in plasma lipides after bilateral nephrectomy or ligation of the ureters have been demonstrated in cats (1), rabbits $(2)$, dogs $(3,4)$ and monkeys $(4)$. These findings led to the hypothesis that the kidney exerts a regulatory influence on plasma lipides (3). The observation that renal venous blood from normal rabbits counteracted the hyperlipemia following nephrectomy supported this concept (5). Peripheral venous or renal blood obtained from rabbits with damaged tubules did not counteract the lipemia, and it was therefore concluded that a lipide regulating factor was produced by normal tubular cells (5). Jiménez Díaz and CastroMendoza $(6,7)$ reported that a renal extract inhibited the hyperlipemia after bilateral nephrectomy or ureteral ligation in dogs. Svanborg (2), and Dimond, Marques Santos, Mundy, and Calderwood (8) failed to confirm these observations. Since the lipide alterations which occur in the nephrotic syndrome are associated with an increased incidence of atherosclerosis (9) and renal fatty degeneration, an explanation of the cause of hyperlipemia would be of value. The development of the intermittent peritoneal dialysis technique (10) as an effective means of maintaining excretory function provided an opportunity to evaluate further the role of the kidney in the etiology of renal hyperlipemia.

\section{METHODS}

Four male and 5 female mongrel dogs, weighing 14.2 to $17.9 \mathrm{Kg}$., were bilaterally nephrectomized in a single stage operation employing ether or Nembutal anesthesia and a lumbar approach. The postoperative care and maintenance of these animals (hereafter referred to as "maintained" dogs) by the intermittent peritoneal dialysis procedure was previously described (11). Three consecutive two-hour dialyses were performed daily for

1 This work was supported, in part, by grants from the Memphis Heart Association and the Council on Pharmacy and Chemistry of the American Medical Association.

$\dagger$ Deceased, December 10, 1955. the first seven postoperative days; thereafter, two daily dialyses were carried out. A low salt diet which contained 30 per cent fat, 45 per cent carbohydrate and 18 -per cent protein was employed (11), and the dogs were fed via stomach tube an amount of diet equivalent to 54 Cal. per Kg. per day. Prior to and on the 7th and 14th days following nephrectomy, blood samples were withdrawn 12 to 16 hours after lavaging and feeding. The plasma was immediately separated, placed in 95 per cent ethanol, and the lipides were isolated by extraction with alcohol-ether, and re-extracted with petroleum ether. Aliquots of this extract were analyzed for total cholesterol by the procedure of Sperry and Webb (12). Phospholipide phosphorus was determined by the King method (13). Total lipides were initially determined gravimetrically, and later by the Bragdon procedure (14). The triglyceride concentration was determined as the difference between the total lipide value and the phospholipide (lipide $\mathrm{P} \times 25$ ) plus the cholesterol concentration. Non-protein nitrogen (15) also was measured in seven of the nine dogs.

\section{RESULTS}

The mean plasma lipide and non-protein nitrogen concentrations of nine maintained, bilaterally nephrectomized dogs are presented in Table I. The plasma phospholipide and cholesterol concentrations on the 7th and 14th days after nephrectomy showed no significant alterations. The plasma phospholipide/cholesterol ratio following nephrectomy remained normal. The triglyceride and total lipide levels were elevated approximately 26 per cent and 16 per cent, respectively, on the 7 th and 14th days. These values were not significantly different from the control values. No lactescence of plasma was noted in these or other maintained, nephrectomized animals previously studied (11). Statistically significant changes were absent in the plasma lipide concentrations, but the variations in lipide levels were much greater in the maintained, nephrectomized dogs than in normal dogs.

The degree of azotemia as indicated by the nonprotein nitrogen level (Table I) increased approximately fourfold and sixfold on the 7 th and 
TABLE I

The plasma lipide fractions * and non-protein nitrogen concentrations in maintained bilaterally nephrectomized dogs $\dagger$

\begin{tabular}{lccccc}
\hline \hline Group & Phospholipide & Cholesterol & $\begin{array}{c}\text { Neutral } \\
\text { fat }\end{array}$ & Total & $\begin{array}{c}\text { Non-protein } \\
\text { nitrogen }\end{array}$ \\
\hline Control & $214 \pm 18$ & $120 \pm 7$ & $216 \pm 27$ & $550 \pm 22$ & $31 \pm 3$ \\
7-day & $223 \pm 28$ & $144 \pm 17$ & $271 \pm 37$ & $639 \pm 52$ & $128 \pm 10$ \\
14-day & $241 \pm 32$ & $138 \pm 15$ & $274 \pm 43$ & $650 \pm 70$ & $172 \pm 8$ \\
\hline
\end{tabular}

* All values are expressed as $\mathrm{mg}$. per $100 \mathrm{ml}$. of plasma.

† Mean lipide values and standard errors are derived from 9 animals.

14th days, respectively. No statistical correlation was observed between the elevated NPN levels and the plasma lipide concentrations.

We confirmed the previous reports $(1-4)$ of hyperlipemia following nephrectomy in animals when excretory function was not maintained. Two dogs were sham-operated and three additional dogs were bilaterally nephrectomized but not maintained by peritoneal dialysis. Since nephrotic hyperlipemia is independent of exogenously administered fats (16) and occurs in fasted animals (4), these nephrectomized animals were fasted to minimize vomiting and to prolong life. Two of the nephrectomized dogs lived for seven days; the third dog lived for six days. In unmaintained, nephrectomized dogs, the mean plasma phosphatide concentration increased from 243 to $366 \mathrm{mg}$. per cent, or a mean 55 per cent elevation. The mean plasma total lipide concentration increased a comparable 56 per cent above the initial value, i.e., from $660 \mathrm{mg}$. per cent to $1,060 \mathrm{mg}$. per cent. All three dogs showed an elevation in blood lipide concentrations. In contrast to the lipide increases noted in the unmaintained, nephrectomized dogs, the sham-operated fasted dogs showed a mean decrease from 290 to $200 \mathrm{mg}$. per cent, or a 31 per cent depression in the phospholipide level and a mean reduction from 680 to $550 \mathrm{mg}$. per cent in the total lipide fraction. Hematocrit values did not change in any of the five dogs. Opalescence of plasma did not occur in the three unmaintained, nephrectomized animals, but a significant hyperlipemia was uniformly observed $(P<.01)$. This lipide increment in the unmaintained, nephrectomized dogs is especially significant since the control, sham-operated dogs showed a marked decrease in plasma lipide levels.

The absence of lipide alterations in the maintained, nephrectomized dogs might have resulted from a loss of lipide in the dialysate. This possibility was investigated by studying the plasma lipides of a normal sham-operated dog in which the intermittent peritoneal dialysis technique was carried out for seven days. No decline in any of the plasma lipide fractions occurred in this animal. The dialysis fluid of a nephrectomized dog contained no cholesterol, and the plasma cholesterol concentration in another maintained, nephrectomized dog, prior to and immediately after the morning dialysis, was unaltered. These observations make it unlikely that the absence of hyperlipemia in the maintained, nephrectomized dogs results from a loss of lipide in the dialyzing fluid.

\section{DISCUSSION}

Numerous investigators have studied the effects of renal ablation on the plasma lipides. Nekludow (1) noted a progressive increase in plasma cholesterol after bilateral nephrectomy or ureteral ligation in cats. Heymann (3) noted a rise in total lipide and cholesterol in dogs after bilateral nephrectomy or mercury poisoning and suggested the existence of a tubular apparatus for regulating blood lipides. Winkler, Durlacher, Hoff, and Man (4) confirmed and expanded the observations of hyperlipemia in nephrectomized monkeys and dogs.

Svanborg listed the possible causes of renal hyperlipemia as interruptions in the (a) excretory function of the kidney, (b) internal secretory activity of the kidney, or (c) metabolic function of the kidney $(2,17)$. Svanborg concluded that the absence of renal metabolic activity causes the elevation in blood lipides of nephrectomized animals. Our present findings of unaltered lipide levels in maintained bilaterally nephrectomized dogs do not support this conclusion. 
Maintenance of bilaterally nephrectomized dogs by the peritoneal dialysis technique is associated with normal liver function, as evaluated by various metabolic and excretory liver function tests (18). Since the liver is the main organ for regulation of plasma lipides in the dog, it is entirely possible that our findings may be credited to maintenance of normal liver function by keeping the animal essentially free of toxic material(s).

Friedman and Byers (19) demonstrated that the accumulation of bile acid in plasma is a condition sufficient in itself to initiate the hepatic mechanism responsible for hypercholesteremia. Rosenman, Friedman, and Byers (20) also suggested a possible relationship between hypercholatemia and hypercholesteremia in clinical and experimental nephrosis, as well as in bilaterally nephrectomized animals (19). When the cholate: cholesterol relationship in normal rats given cholate by intravenous injection is compared with that in nephrectomized animals, it is suggestive that the rise in cholesterol concentration noted in the latter animals may exceed that which could be accounted for by the plasma cholate elevation.

In our present study, it is possible that removal of diffusible cholate from plasma of maintained nephrectomized dogs may have aided in preventing the hyperlipemia and hypercholesteremia otherwise observed.

Bloor (21) suggested that nephrotic hyperlipemia is caused by a general metabolic disturbance. Peters and Van Slyke stated that there is "no inverse relation between the serum lipides and blood non-protein nitrogen or any other index of renal excretory function" (22). It has been demonstrated, however, that hyperlipemia occurs in ureter-ligated dogs only as renal function is affected (23). The non-protein nitrogen levels observed in our maintained dogs 7 and 14 days following nephrectomy were much lower than the non-protein nitrogen levels found in non-maintained dogs 12 to 24 hours after nephrectomy (7, 23 ), at which time minor changes, if any, have occurred in the plasma lipide fractions $(7,23)$.

In consideration of the significantly different results obtained in the unmaintained and maintained nephrectomized dogs, it is apparent that the lipide changes in unmaintained nephrectomized animals are not the result of a loss in renal hor- monal or metabolic activity. Our present findings question the previously proposed concepts of renal endocrine or metabolic factors which regulate plasma lipide metabolism.

\section{SUMMARY}

In bilaterally nephrectomized dogs maintained for 14 days by intermittent peritoneal dialysis, no significant alteration occurred in the plasma phospholipide and cholesterol levels. Plasma total lipide and triglyceride concentrations increased only slightly. Renal hyperlipemia induced by bilateral nephrectomy apparently results from metabolic disturbances secondary to the loss of renal excretory function and not from a loss of renal metabolic or hormonal control.

\section{REFERENCES}

1. Nekludow, W. N., Uber den Einfluss des Ausfalls der Nierenfunktion auf den Cholesterinstoffwechsel. (Zur Frage der experimentellen Urämie.) Ztschr. f. d. ges. exper. Med., 1925, 47, 70 .

2. Svanborg, A., Studies on renal hyperlipemia. Acta med. Scandinav., 1951, 141, Suppl. 264.

3. Heymann, W., Renal hyperlipemia in dogs. Science, 1942, 96, 163 .

4. Winkler, A. W., Durlacher, S. H., Hoff, H. E., and Man, E. B., Changes in lipid content of serum and of liver following bilateral renal ablation or ureteral ligation. J. Exper. Med., 1943, 77, 473.

5. Miyazaki, H., Control of blood cholesterol by the kidney. J. Chosen Med. Assoc., 1934, 24, 279.

6. Jiménez Díaz, C., and Castro-Mendoza, H., The role of the kidney in fat metabolism. Bull. Inst. Med. Research, 1948, 1, 1.

7. Jiménez Díaz, C., and Castro-Mendoza, H., Various types of renal extracts in the prevention of postnephrectomy biochemical effects. Bull. Inst. Med. Research, 1952, 5, 83.

8. Dimond, E. G., Marques Santos, E., Mundy, W., and Calderwood, B., An attempt to establish the presence of a hypocholesterolemic factor in the renal blood of dogs. J. Lab. \& Clin. Med., 1953, 42, 800.

9. Steiner, A:, and Domanski, B., Serum cholesterol and atherosclerosis in chronic glomerulonephritis. Am. J. M. Sc., 1942, 204, 79.

10. Grollman, A., Turner, L. B., and McLean, J. A., Intermittent peritoneal lavage in nephrectomized dogs and its application to the human being. Arch. Int. Med., 1951, 87, 379.

11. Houck, C. R., Problems in maintenance of chronic bilaterally nephrectomized dog. Am. J. Physiol., 1954, 176, 175. 
12. Sperry, W. M., and Webb, M., A revision of Schoenheimer-Sperry method for cholesterol determination. J. Biol. Chem., 1950, 187, 97.

13. King, E. J., The colorimetric determination of phosphorus. Biochem. J., 1932, 26, 292.

14. Bragdon, J. H., Colorimetric determination of blood lipides. J. Biol. Chem., 1951, 190, 513.

15. Koch, F. C., and McMeekin, T. L., A new direct nesslerization micro-kjeldahl method and a modification of the Nessler-Folin reagent for ammonia. J. Am. Chem. Soc., 1924, 46, 2066.

16. Page, I. H., and Farr, L. E., The influence of high and low fat diets and thyroid substance on plasma lipids of nephrotic patients. J. Clin. Invest., 1936, $15,181$.

17. Svanborg, A., Views on renal hyperlipemia. Acta med. Scandinav., 1953, 147, 60.

18. Gilmer, R. E., Jr., and Houck, C. R., Liver function in the bilaterally nephrectomized dog maintained by intermittent peritoneal dialysis. Am. J. Physiol., 1954, 179, 639.

19. Friedman, M., and Byers, S., Production and excretion of cholesterol in mammals. VI. Bile acid accumulation in production of hypercholesteremia occurring after biliary obstruction. Am. J. Physiol., 1952, 168, 292.

20. Rosenman, R. H., Friedman, M., and Byers, S. O., Observations concerning the cholate:cholesterol relationship in clinical and experimental nephrosis. J. Clin. Invest., 1953, 32, 121.

21. Bloor, W. R., The blood lipoids in nephritis. J. Biol. Chem., 1917, 31, 575.

22. Peters, J. P., and Van Slyke, D. D., Quantitative Clinical Chemistry. 2nd ed., Baltimore, Williams and Wilkins Co., 1946, p. 531.

23. Castro-Mendoza, H., and Jiménez Díaz, C., Fats of plasma after the ligature of the ureters. Bull. Inst. Med. Research, 1949, 2, 239. 